\title{
Impactos socioeconômicos do microcrédito: o caso do Nossocrédito no Espírito Santo
}

\author{
Sávio Bertochi Caçador ${ }^{1}$ \\ Banco de Desenvolvimento do Espírito Santo (Bandes)
}

\begin{abstract}
Este trabalho objetiva verificar os impactos de um programa estadual de microcrédito - o Nossocrédito do Espírito Santo - sobre indicadores socioeconômicos. Para isso são estimados três modelos distintos visando avaliar: i) se o Nossocrédito tem sido direcionado para os municípios de menor grau de desenvolvimento e/ou localizados no interior do estado; ii) se o programa tem contribuído para melhorar o desenvolvimento municipal; iii) se o Nossocrédito tem contribuído para reduzir a pobreza. As estimativas foram conduzidas com o método de mínimos quadrados ordinários e usa dados municipais de 2006 a 2010. Os principais resultados encontrados são: i) o Nossocrédito é direcionado para os municípios do interior, mas não para os de menor grau de desenvolvimento; ii) o programa contribui para a melhoria do indicador municipal de desenvolvimento utilizado; iii) o Nossocrédito não contribui para a redução da pobreza.
\end{abstract}

Palavras-chave: microcrédito; desenvolvimento regional; Espírito Santo.

Impactos socioeconómicos de microcredito: el caso de Nossocrédito en Espírito Santo Este trabajo tiene como objetivo comprobar el impacto de un programa de microcredito - el Nossocrédito del Espírito Santo - en indicadores socio-económicos. Para esto son Estimado tres modelos distintos para evaluar: i) si el Nossocrédito ha sido dirigido a las ciudades de menor grado de desarrollo o ubicado dentro de lo estado; ii) si el programa ha contribuido a mejorar el desarrollo municipal; iii) si el Nossocrédito ha contribuido a reducir la pobreza. Las estimaciones se realizaron con el método de Mínimos Cuadrados Ordinarios y utiliza los datos municipales 2006 2010. Los principales resultados son: i) la Nossocrédito está dirigida a los municipios del interior, pero no para los de menor grado de

\footnotetext{
* DOI: http://dx.doi.org/10.1590/0034-76121701

Artigo recebido em 25 ago. 2013 e aceito em 29 jul. 2014.

${ }^{1}$ Vale a ressalva de que as opiniões contidas neste estudo não refletem a opinião do Banco de Desenvolvimento do Espírito Santo (Bandes) ou de algum outro membro dessa instituição. $O$ autor agradece os comentários e sugestões de dois pareceristas anônimos da Revista de Administração Pública, que muito contribuíram para aprimorar a versão anterior do presente trabalho. Vale a ressalva usual de que erros e idiossincrasias remanescentes devem-se única e exclusivamente ao autor.
} 
desarrollo; II) el programa contribuye a la mejora del indicador de desarrollo municipal utilizado; III) la Nossocrédito no contribuye a la reducción de la pobreza.

Palabras clave: microcredito; desarrollo regional; Espírito Santo.

Socioeconomic impacts of microcredit: the case of Nossocrédito in Espírito Santo, Brazil This paper aims to check the impacts of a state microcredit program - Nossocrédito of Espírito Santo, Brazil — on socioeconomic indicators. In order to do it it is estimated three distinct models to evaluate: i) if Nossocrédito has been directed to the cities of lesser degree of development and/or located inside the state; ii) if the program has contributed to improve the municipal development; iii) if Nossocrédito has contributed to reduce poverty. The estimates were conducted with the Ordinary Least Squares method and uses municipal data from 2006 up to 2010. The main results are: i) Nossocrédito is directed to the municipalities of the countryside, but not for those of lesser degree of development; ii) the program contributes to the improvement of the municipal development indicator used; iii) Nossocrédito does not contribute to poverty reduction.

KEYWords: microcredit; regional development; Espírito Santo.

\section{Introdução}

O microcrédito tem sido o principal instrumento das chamadas políticas de geração de emprego e renda que surgiram mundo afora. Nota-se, porém, que esse mecanismo possui uma lógica distinta das políticas assistencialistas tradicionais, visando criar oportunidades de inserção dos beneficiários no processo produtivo. Não se constitui, portanto, em políticas de doações ou subsídios, mas de viabilização de alternativas concretas de geração de emprego e renda pelos beneficiários.

O estudo aqui em tela trata especificamente do Nossocrédito, programa de microcrédito criado em 2003 pelo governo do Espírito Santo. Ele é executado pelo Banco de Desenvolvimento do Espírito Santo (Bandes) em convênio com o governo estadual por meio da Agência de Desenvolvimento das Micro e Pequenas Empresas e do Empreendimento (Aderes), Banco do Estado do Espírito Santo (Banestes), Serviço Brasileiro de Apoio às Micro e Pequenas Empresas (Sebrae/ES) e prefeituras municipais. O seu objetivo é avaliar o impacto socioeconômico do Nossocrédito nos municípios capixabas.

Para se ter uma ideia da dimensão do Nossocrédito, vale a pena citar alguns números. Em 2012, por exemplo, foram mais de 18 mil operações aprovadas nos 78 municípios capixabas, num total aprovado de mais de $\mathrm{R} \$ 87,3$ milhões. Isso representou $0,46 \%$ do saldo de operações de crédito no estado naquele ano. ${ }^{2}$

\footnotetext{
${ }^{2}$ Segundo dados da Estatística Bancária Mensal (Estban) do Banco Central do Brasil (BCB), que contempla saldos das principais rubricas de balancetes dos bancos comerciais e dos bancos múltiplos com carteira comercial, por município, o total de operações de crédito realizadas por estas instituições no Espírito Santo, em 2012, foi de pouco mais de R\$ 19 bilhões. Infelizmente o BCB ainda não disponibiliza dados regionais de microcrédito.
} 
Este trabalho objetiva verificar os impactos de um programa estadual de microcrédito — o Nossocrédito do Espírito Santo - sobre indicadores socioeconômicos. Para isso são estimados três modelos distintos visando avaliar: i) se o Nossocrédito tem sido direcionado para os municípios de menor grau de desenvolvimento e/ou localizados no interior do estado; ii) se o programa tem contribuído para melhorar o desenvolvimento municipal; iii) se o Nossocrédito tem contribuído para reduzir a pobreza. As estimativas foram conduzidas com o método de mínimos quadrados ordinários (MQO) e usa dados municipais de 2006 a 2010.

O restante do texto se divide em cinco seções. A segunda seção apresenta algumas considerações sobre a importância do microcrédito para o desenvolvimento econômico e resgata os principais estudos sobre microcrédito no Brasil e no Espírito Santo. A terceira seção apresenta um panorama geral da experiência brasileira recente com microcrédito. Já a quarta seção traz uma breve apresentação institucional do Nossocrédito, bem como mostra seus principais dados. A quinta seção faz uma avaliação do impacto do Nossocrédito em indicadores socioeconômicos dos municípios capixabas. Na última seção, por sua vez, fazem-se as considerações finais.

\section{Revisão de literatura sobre microcrédito}

\subsection{Microcrédito e desenvolvimento}

A presente seção apresenta algumas considerações sobre a importância do microcrédito para o desenvolvimento econômico, mais especificamente para o desenvolvimento regional. Mas, antes disso, alguns apontamentos teóricos são necessários.

A partir dos anos 1990, com a publicação do trabalho de King e Levine (1993), reacendeu-se o debate na teoria econômica sobre a relação entre desenvolvimento financeiro e crescimento econômico. Desde então, vários trabalhos empíricos têm sido realizados mundo afora para comprovar se essa relação de fato existe, usando diversas técnicas estatísticas. Contudo, o tema ainda é controverso, já que alguns textos mostram evidências consistentes de que existe uma correlação positiva entre desenvolvimento financeiro e crescimento econômico e outros indicam que a relação entre as duas variáveis é bidirecional, ou seja, crescimento econômico e desenvolvimento financeiro têm impactos positivos e mútuos um sobre o outro.

No Brasil, a literatura econômica nacional acompanhou esse debate mundial fazendo análises sobre a realidade brasileira. Trabalhos usando técnicas econométricas diversas mostraram que é positiva a causalidade entre desenvolvimento financeiro e crescimento econômico para o país, contrariamente ao trabalho de Reichstul e Lima (2006), que identificaram uma causalidade bidirecional entre as duas variáveis.

Além disso, existe uma corrente de pesquisa com relação ao tema crédito e crescimento que mostra que o bom funcionamento do sistema financeiro não é alcançado devido à existência de falhas de mercado. Nessa linha, Stiglitz e Weiss (1981) apontam a assimetria de informações como uma das principais falhas de mercado, e que tem efeitos particulares no 
mercado financeiro. O principal efeito é o racionamento de crédito, em que os emprestadores se recusam a emprestar mesmo que o tomador esteja disposto a pagar juros mais altos.

Um tipo específico de falhas de mercado que pode ser observado nos países em desenvolvimento constitui aquilo que se convencionou chamar de incompletude dos mercados. Segundo Stiglitz (1993), em economias menos desenvolvidas os mercados financeiros são incompletos, isto é, os mercados de crédito são fracos e os mercados acionários, muitas vezes, inexistem. Isso gera duas situações: de um lado, os bancos tendem a privilegiar os empréstimos de curto prazo, e, por outro lado, haveria, por parte dos empreendedores, um desinteresse em financiar projetos que, embora tenham um alto retorno social, têm uma baixa rentabilidade e alto risco.

Por fim, no referencial pós-keynesiano, Dow $(1982,1987,1990)$ aplica os conceitos de não neutralidade da moeda, incerteza e preferência pela liquidez às categorias centro e periferia. Esta última caracteriza-se por possuir uma trajetória de crescimento mais instável, cuja dinâmica é exógena, com alta propensão a importar, e tanto o grau de desenvolvimento dos mercados financeiros como o grau de liquidez dos ativos são baixos. Assim, o grau de incerteza nessas economias tende a ser mais elevado do que no centro e, portanto, a preferência pela liquidez dos agentes econômicos, inclusive as instituições financeiras, também é mais elevada.

Esse quadro tende a gerar um círculo vicioso, em que os bancos tendem a ofertar volumes relativamente menores de crédito para as economias periféricas, deslocando recursos para as regiões centrais e agravando as diferenças estruturais existentes (Nogueira, Crocco e Santos, 2010). "Não há mecanismos endógenos capazes de romper essa dinâmica concentradora. Portanto, a única forma de revertê-la é a introdução de elementos exógenos" (Amado, 2010:228), e o elemento exógeno é justamente o Estado. Neste sentido, instituições de atuação regional seriam preferíveis às de atuação nacional, segundo Menezes e colaboradores (2007:303).

Em função de todos os elementos apontados anteriormente (quais sejam, a importância do crédito para o crescimento econômico; a existência de falhas de mercado, como a assimetria de informação, limita o crédito a pessoas de baixa renda, empreendedores informais, micro e pequenas empresas, justamente o público-alvo de programas de microcrédito como o Nossocrédito; e as diferenças entre as regiões centrais e as periféricas, que provocam a concentração de crédito nas primeiras), o microcrédito assume papel de destaque na promoção do desenvolvimento econômico, pois ele visa conceder crédito àqueles segmentos da sociedade que encontram dificuldade de consegui-lo no sistema financeiro convencional.

No caso do Brasil, Freitas e Paula (2010) mostram, por exemplo, que o crédito é regionalmente concentrado no país: segundo eles, em 2007, das 2.437 instituições financeiras brasileiras, a região Sudeste continha 56\% delas, ou seja, 1.375, com São Paulo e Rio de Janeiro concentrando 40\% (976) das instituições brasileiras. Eles também mostram que o estado de São Paulo apresenta uma relação crédito/Produto Interno Bruto (PIB) bastante superior aos demais estados brasileiros. Em 1994 essa relação era de 41,8\%, subindo para 44,1\% em 2006, percentual bem distante dos valores observados para os outros estados.

Nessa linha, estudo do Instituto de Pesquisa Econômica Aplicada (Ipea, 2011) indica melhora da bancarização (percentual da população com conta bancária) no Brasil: essa taxa 
passou de $16,1 \%$, em 2005, para 60,5\%, em 2010. Todavia, esse avanço do acesso aos bancos foi maior em regiões mais desenvolvidas ou em categorias privilegiadas da população — como os brasileiros com maior nível de escolaridade e maior renda.

Por conta desses fatores, o desenvolvimento financeiro é importante para o desenvolvimento econômico de uma região e o microcrédito pode contribuir para isso. Vale destacar o que se entende por desenvolvimento financeiro: segundo Barger (1998), ele compreende os conceitos de aprofundamento, que se refere ao aumento dos ativos financeiros como percentagem do PIB, e de alargamento, que consiste no aumento do número e da variedade de participantes e instrumentos do mercado financeiro. $\mathrm{O}$ microcrédito pode contribuir para o desenvolvimento financeiro nos dois aspectos: no aprofundamento, ao possibilitar um aumento no volume de crédito; e no alargamento, ao permitir que aqueles segmentos que normalmente não acessam o sistema financeiro tradicional possam fazê-lo.

Finalmente, pode-se dizer que o desenvolvimento financeiro, via microcrédito, pode viabilizar o crescimento econômico de regiões menos desenvolvidas ao conceder crédito a projetos de investimentos considerados de maior risco e menor retorno pelo sistema financeiro convencional, ajudando a promover um desenvolvimento regionalmente mais equilibrado do país. Ademais, ao financiar categorias menos privilegiadas, como a população de menor renda e/ou menor escolaridade, promove a inclusão social e amplia o mercado consumidor e o bem-estar da sociedade (Estrella, 2008).

\subsection{Literatura empírica sobre microcrédito}

A presente seção apresenta, de forma sucinta, os principais textos sobre microcrédito no Brasil, num primeiro momento, e no Espírito Santo, num segundo momento.

O trabalho de Braga e Toneto Jr. (2000) discute as dificuldades de financiamento das microempresas dentro da lógica do sistema financeiro tradicional e como o microcrédito pode resolver esse problema. O primeiro ponto do trabalho foi mostrar por que as microempresas são excluídas dos financiamentos tradicionais na presença de informações assimétricas. Em seguida, eles apresentaram a experiência do Grameen Bank para mostrar como arranjos contratuais específicos podem viabilizar o financiamento de pequenos empreendimentos. E, ao final, apresentaram a experiência brasileira com microcrédito, destacando-se que o Programa de Geração de Emprego e Renda (Proger), enquanto executado dentro das regras do Sistema Financeiro tradicional, não conseguia atingir seus objetivos, o que já apontava para a necessidade de se criar uma rede de instituições mais flexíveis e que estejam mais próximas dos tomadores para garantir a viabilidade do microcrédito.

Já Mazzutti (2005) investiga se os programas de microcrédito são capazes de estender empréstimos para as pessoas pobres sem contar com subsídios. Para tanto, lançou-se mão de estudos de caso de quatro programas brasileiros com a intenção de evidenciar um possível dilema entre foco e sustentabilidade financeira. A constatação foi de que as instituições brasi- 
leiras têm enfrentado dificuldades nas duas frentes, já que nenhuma apresentou sustentabilidade financeira e um compromisso explícito com a redução da pobreza.

Neri e Giovanini (2005), por sua vez, realizam uma análise empírica dos determinantes do uso de crédito a partir de amostra de 50 mil empresas formais e informais por conta própria ou empregadoras até cinco empregados a partir da pesquisa Economia Informal e Urbana (Ecinf/IBGE). O mercado de microcrédito se revelou incipiente: apenas 13,7\% dos nanonegócios apresentavam dívida pendente, a concentração dos estoques de dívida entre os $10 \%$ mais altos valores nesse segmento é de $98,5 \%$ contra $60,8 \%$ do faturamento e $59,4 \%$ do lucro. Complementarmente, 7\% dos nanonegócios obtiveram acesso a crédito nos três meses anteriores à pesquisa. Foi apresentado o padrão de correlações do uso do crédito produtivo popular com outras variáveis, baseadas em um modelo logístico estimado a partir dos microdados da Ecinf/IBGE. Os autores constataram também que alguns elementos do capital social como participação em cooperativas, indicadores de formalidade e posse de equipamentos apresentam correlação significativa com o acesso a crédito.

Com relação ao Crediamigo do BNB, Neri (2008) analisa a operação desse programa, que aplica a metodologia de grupo solidário nas áreas urbanas de menor renda no país. Verificou-se um aumento de uso do crédito produtivo no Nordeste urbano pronunciado em relação à parte urbana restante do país durante os seis primeiros anos do programa. Além disso, aferiu-se um impacto real de 30,7\% sobre o lucro operacional dos clientes e um incremento nas despesas de consumo das famílias de 13\% entre a primeira e a última operação. Por fim, deve-se registrar que o programa gera lucro de cerca de $\mathrm{R} \$ 50 /$ ano por operação levando em conta todos os custos, inclusive o de oportunidade financeira.

Por outro lado, Pimentel e Kerstenetzky (2008) estudam os efeitos da Lei no 10.735/2003, que estabelece a aplicação de recursos correspondentes a $2 \%$ dos depósitos à vista captados pelos bancos comerciais exclusivamente em operações de microcrédito. Dado que os bancos comerciais têm de um modo geral preferido não aplicar os recursos previstos na lei, o trabalho tem como objetivo tentar entender essa atitude. Para tal, eles aplicaram um questionário simples a um conjunto previamente identificado de atores-chave do segmento de microfinanças. Os resultados apontaram essencialmente a questão da incerteza como central na decisão dos bancos comerciais de não entrar no microcrédito para valer.

Freitas e Ribeiro (2009) explicam a performance empreendedora de tomadores de microcrédito com base nos recursos pessoais e nas atividades organizacionais. Eles fizeram a associação entre as duas dimensões e o desempenho do negócio através de uma análise de agrupamento baseada na técnica de Chi-Square Automation Interaction Detection e tendo por base um banco de dados do Programa Crediamigo contendo 9.037 registros de empreendedores da região Nordeste. Os resultados apresentaram implicações teóricas e práticas como a importância da variável idade na explicação do desempenho empreendedor, e escolaridade e gênero que também aparecem de maneira significativa, influenciando diferentes grupos de empreendedores.

Arraes e Silva (2010) analisam o mercado de microcrédito sob o foco da demanda, buscando identificar a forma de atuação dos pequenos empresários e sua rotatividade no mercado. Para tanto, foram desenvolvidos, inicialmente, dois modelos de escolha discreta multino- 
miais que contemplassem e mensurassem os fatores determinantes na decisão do tomador em ser usuário de microcrédito, dadas as suas características pessoais em face das condições do micronegócio. O terceiro modelo, de escolha discreta binária, objetivou estimar a chance de o tomador deixar de ser usuário de microcrédito levando-se em conta a oferta e o desempenho do próprio micronegócio. Os resultados obtidos permitiram concluir de uma forma geral que os pequenos empresários procuram manter-se no mercado buscando expandir seus negócios, tendo o microcrédito como um dos instrumentos iniciais para esse fim.

Já o texto de Neri e Medrado (2010) faz uma análise quantitativa do impacto do Crediamigo sobre o acesso a crédito de pequenas unidades produtivas, realizada a partir de microdados das pesquisas Ecinf/IBGE de 1997 e 2003. Utiliza como estratégias de identificação de impacto do programa a sua escala e abrangência regional diferenciada, através do método de diferenças em diferenças em data anterior e posterior ao início do programa, e uma vasta gama de variáveis de acesso a crédito. Em termos substantivos, eles concluíram que, apesar da incipiência do crédito produtivo popular no país, há uma experiência de microcrédito na região urbana mais pobre do Brasil, baseada em aval solidário, proporcionando aumento e nível de acesso a crédito superior ao observado no resto do país.

Soares e colaboradores (2011) investigam a importância de alguns condicionantes facilitadores da saída da condição de pobreza dos clientes do Crediamigo, bem como sua velocidade de ascensão nesse programa de microcrédito produtivo. Para isso, eles utilizaram um modelo logístico de probabilidade de saída da pobreza, aplicado a clientes que ingressaram no programa com renda per capita familiar abaixo de linhas tradicionais delimitadoras desse estado de pobreza. Os resultados demonstram que os fatores facilitadores de ascensão dos mais pobres não se diferenciam dos fatores tradicionais para investidores do topo da pirâmide produtiva, isto é, uma probabilidade de sucesso maior ocorre para aqueles mais dotados de capital humano e de colaterais produtivos. Quanto às características dos empréstimos, os autores verificaram que prazos menores de pagamentos, com valores medianos para empréstimos iniciais, facilitam o sucesso do nanoempresário. Eles estimaram também uma velocidade média de saída da pobreza entre $6 \%$ e $8 \%$ ao ano durante os primeiros cinco anos de programa.

Chaves (2011) investiga possíveis variáveis que estão dificultando o crescimento da incipiente indústria do microcrédito no Brasil e apontou algumas soluções para esse problema. Ele identificou que é pequena a participação e tímida a evolução do microcrédito no país; é reduzido o número de atores e relevante a participação de entes públicos, suprindo a incipiente contribuição do mercado privado; o sistema financeiro nacional é considerado sólido e bem regulado, mas seletivo, excluindo um significativo número de pessoas pobres; a região Nordeste tem recebido pouca atenção das instituições bancárias, do cooperativismo de crédito e das Sociedades de Crédito ao Microempreendedor e às Empresas de Pequeno Porte (SCMEPP), e seu desenvolvimento socioeconômico é muito dependente da atuação do BNB. Ele concluiu que a expansão das atividades de microcrédito é uma necessidade urgente e o Estado deve ser o principal protagonista para liderar esse processo. Por outro lado, a implementação de novas regras formais e a superação de regras informais serão fundamentais para a construção de um futuro promissor para o segmento. 
Por fim, Mota e Santana (2011) estudam o efeito sobre a redução da pobreza de variáveis relevantes colocadas pela literatura, como a concentração de renda, o tamanho econômico, a educação e, sobretudo, o microcrédito. O objetivo é verificar se as operações de microcrédito podem influenciar na diminuição da pobreza. A avaliação foi realizada a partir do programa Crediamigo usando dados de 1.243 municípios, em 2000. Foram realizadas estimações dos fatores determinantes da pobreza utilizando o método dos mínimos quadrados ordinários, em três cortes de dados. Os resultados corroboraram, de um modo geral, os achados da literatura para as variáveis tradicionalmente utilizadas. No caso do microcrédito, mostra-se que este pode influenciar a diminuição da pobreza na região.

Com relação ao Espírito Santo, Giuberti (2008) analisa a política de microcrédito estadual a partir dos processos de formulação e implementação do Programa Nossocrédito, o que compreende o período entre 2003 e abril de 2008. A autora utiliza dados primários coletados por meio de entrevistas semiestruturadas com atores-chave do Programa, dados secundários obtidos por meio de documentos oficiais e literatura acadêmica especializada sobre o tema. Ela concluiu que o arranjo institucional arquitetado para a implementação do Nossocrédito apresenta mecanismos que garantem sustentabilidade ao Programa: fonte de recurso robusta, capilaridade, diluição dos custos entre os parceiros e oferta de crédito a taxa reduzida. Mas, apesar de sua potencialidade, tem alcance limitado e não atende a população mais pobre da categoria "baixa renda".

Já Dutra (2010) estudou a concessão do microcrédito e sua relação com a inadimplência a partir de uma amostra de dados de operações de microcrédito, deferidas pelo Banestes e Bandes. Com a utilização de dados cadastrais de clientes (6.349 clientes do Banestes, com 21,4\% de inadimplência, e 81 do Bandes, com 19,8\% de inadimplência), procurou identificar as variáveis significativas que pudessem explicar a probabilidade de inadimplência de uma operação de microcrédito. Para tanto, utilizou-se da técnica de Regressão Logística com variáveis explicativas como valor de crédito, número de parcelas, valor das parcelas, renda mensal, gênero (dummy, sendo atribuído o valor um para homem e zero para mulher), número de empregos a serem gerados com o crédito e percentual do comprometimento da renda mensal com o valor das parcelas. Os resultados obtidos mostram que essas variáveis não foram satisfatórias para explicar a probabilidade de inadimplência.

Finalmente, Premoli (2011) verifica determinantes da eficácia operacional das agências do Nossocrédito no cumprimento das metas do programa e a eficiência na alocação de recursos a partir de dados de 2011. Para a aferição da eficácia foi utilizado o modelo de regressão logística e seis variáveis foram significantes: agências autorizadas a operar outras linhas, maior jornada de trabalho, linha telefônica disponível para a agência, visitas do assistente técnico, campanha de divulgação do programa e tempo disponibilizado pela agência para cobrança dos clientes inadimplentes. Já para a avaliação da eficiência se utilizou a análise envoltória de dados e os resultados mostraram grande heterogeneidade dos municípios quanto aos benefícios gerados pelo crédito. Apenas Guaçuí, Pancas e Piúma obtiveram índice máximo de eficiência, demonstrando que os demais municípios precisavam aumentar suas operações de crédito para se tornarem mais eficientes. 
Baseando-se nas referências citadas anteriormente, o presente trabalho buscará evidenciar os efeitos econômicos e sociais do Nossocrédito nos municípios do Espírito Santo. Do ponto de vista empírico, o artigo contribui na metodologia de análise da efetividade do microcrédito ao usar indicadores socioeconômicos municipais. Os estudos referenciados no artigo focam a evolução socioeconômica dos microempreendedores e não indicadores socioeconômicos agregados para os municípios. Do ponto de vista de avaliação do Nossocrédito, o presente trabalho apresenta resultados bem diferentes dos encontrados em Giuberti (2008) — o programa não atende os mais pobres — , Dutra (2010) — determinantes da inadimplência - e Premoli (2011) — eficácia operacional das agências e eficiência na alocação de recursos.

\section{Programa Nossocrédito}

\subsection{Desenho institucional}

O Programa Nossocrédito foi instituído pelo Governo do Estado do Espírito Santo através do Decreto Estadual nº 1.203-R/2003, constituindo uma modalidade especial de crédito, e foi estruturado visando à inclusão econômica e social de empreendedores de pequenos negócios, mediante a concessão de crédito conjugado com capacitação e assistência técnica aos tomadores. A estratégia foi a de mobilizar e integrar instituições como Bandes, Banestes, Secretaria Estadual do Trabalho e Ação Social, prefeituras municipais, Comissão Estadual do Trabalho e Comissões Municipais do Trabalho, de modo a utilizar e otimizar as estruturas já existentes nesses órgãos públicos e formar uma rede articulada e integrada por meio de convênios específicos firmados entre o Estado e as referidas instituições.

A meta estabelecida inicial era a implantação de quatro Unidades Municipais de Microcrédito (UMMs) como pilotos entre julho e outubro de 2003. A implantação no restante do estado se daria em quatro anos, ou seja, até dezembro de 2006. Foram selecionados nessa primeira fase, como pilotos, os municípios de Viana, Cachoeiro de Itapemirim, Nova Venécia e Presidente Kennedy.

De acordo com o planejamento inicial, a expansão do Programa deveria alcançar 24 municípios em 2004, 27 municípios em 2005 e 27 municípios em 2006, totalizando os 78 municípios, com um aporte de recursos mínimo de $\mathrm{R} \$ 45$ milhões ao ano, provenientes do fundo a ser criado. De fato, o que ocorreu foi que somente em 2009 todos os municípios tinham pelo menos uma UMM.

A partir de meados do segundo semestre de 2004, o Programa Nossocrédito passou a receber recursos do Fundo para Financiamento de Micro e Pequenos Empreendimentos e Projetos Sociais (Fundapsocial), instituído pela Lei Estadual no 7.829/2004, e regulamentado pelo Decreto Estadual no $1.366-\mathrm{R} / 2004$. Outra parte do funding necessário à execução do Programa vem do Banestes, mais especificamente, dos $2 \%$ de compulsório sobre os depósitos à vista, conforme Lei Federal no $10.735 / 2003$. 
Em 25 de outubro de 2005 foi publicado o Decreto Estadual no ${ }^{-1.565-R, ~ m u d a n d o ~ a ~ e s t r u-~}$ tura do Programa Nossocrédito, transferindo a responsabilidade da coordenação do Programa para o Comitê Executivo do Fundapsocial (Comef) e para sua Secretaria Executiva, exercida pelo Bandes. Atualmente, o Programa Nossocrédito é executado pelo Bandes em convênio com o Governo do Estado por meio da Aderes, Banestes, Sebrae/ES e Prefeituras Municipais.

\subsection{Características dos clientes do Nossocrédito}

Depois de uma descrição institucional do Nossocrédito, parte-se para um exame das informações específicas dos seus clientes. A tabela 1 traz informações referentes ao período 2011-12, o que representa $40,8 \%$ do total de operações aprovadas desde o início do programa em setembro de 2003.

Tabela 1

Caracterização dos clientes do Nossocrédito

\begin{tabular}{|c|c|c|c|c|c|}
\hline Variáveis & Discriminação & 2011 & 2012 & Total & $\%$ \\
\hline \multirow{2}{*}{ Sexo } & Feminino & 8.066 & 9.996 & 18.062 & 55,4 \\
\hline & Masculino & 6.508 & 8.004 & 14.512 & 44,6 \\
\hline \multirow{2}{*}{ Segmento } & Urbano & 12.957 & 16.263 & 29.220 & 89,7 \\
\hline & Rural & 1.618 & 1.755 & 3.373 & 10,3 \\
\hline \multirow{2}{*}{ Setor } & Formal & 3.746 & 5.169 & 8.915 & 27,4 \\
\hline & Informal & 10.830 & 12.848 & 23.678 & 72,6 \\
\hline \multirow{3}{*}{ Atividade } & Serviço & 3.778 & 4.502 & 8.280 & 25,5 \\
\hline & Comércio & 8.590 & 10.939 & 19.529 & 60,0 \\
\hline & Indústria & 2.155 & 2.570 & 4.725 & 14,5 \\
\hline \multirow{6}{*}{$\begin{array}{l}\text { Faixa de valor dos } \\
\text { financiamentos }\end{array}$} & De $R \$ 200,00$ a $R \$ 1.000,00$ & 421 & 730 & 1.151 & 3,5 \\
\hline & De $R \$ 1.000,01$ a $R \$ 4.000,00$ & 6.073 & 10.266 & 16.339 & 50,1 \\
\hline & De $R \$ 4.000,01$ a $R \$ 7.500,00$ & 7.847 & 5.009 & 12.856 & 39,4 \\
\hline & De $R \$ 7.500,01$ a $R \$ 10.000,00$ & 43 & 1.302 & 1.345 & 4,1 \\
\hline & De $R \$ 10.000,01$ a $R \$ 12.500,00$ & 23 & 242 & 265 & 0,8 \\
\hline & Acima de $R \$ 12.500,00$ & 170 & 469 & 639 & 2,0 \\
\hline \multirow{3}{*}{ Finalidade } & Fixo & 2.984 & 1.957 & 4.941 & 15,2 \\
\hline & Giro & 10.968 & 15.865 & 26.833 & 82,5 \\
\hline & Misto & 624 & 137 & 761 & 2,3 \\
\hline \multirow{3}{*}{ Renda familiar mensal } & Até $R \$ 1.500,00$ & 2.707 & 2.263 & 4.970 & 15,3 \\
\hline & De $R \$ 1.500,01$ a $R \$ 3.000,00$ & 6.463 & 7.897 & 14.360 & 44,1 \\
\hline & Acima de $R \$ 3.000,00$ & 5.386 & 7.820 & 13.206 & 40,6 \\
\hline
\end{tabular}

Fonte: Bandes (2013). 
Dessa forma, as principais características dos clientes do Nossocrédito são descritas a seguir. Quanto ao gênero, 55,4\% dos clientes são do sexo feminino. No que toca à localização, $89,7 \%$ estão no meio urbano, o que é ratificado pelo fato de $60 \%$ atuarem no comércio. Além disso, $72,6 \%$ são informais. No que diz respeito ao porte dos financiamentos, $93 \%$ são de até R\$ 7,5 mil, 50,1\% estando na faixa de valor entre $\mathrm{R} \$ 1.000,01$ e $\mathrm{R} \$ 4.000,00$. No que tange à finalidade do financiamento, $82,5 \%$ dos clientes o contratam para giro. Por fim, a tabela 1 mostra que $44,1 \%$ dos clientes possuem renda familiar mensal entre $\mathrm{R} \$ 1.500,01$ e $\mathrm{R} \$ 3.000,00$.

Dos dados apresentados anteriormente, dois pontos chamam atenção negativamente e um ponto positivamente:

จ Pontos negativos: i) a maioria dos clientes é informal, apesar de todo aparato legal recente incentivando a formalização; ii) grande parte dos financiamentos é para giro, o que pode ser consequência da característica de gestão de pequenos negócios de ser realizada por pessoas que não têm nível de escolaridade maior, que têm dificuldade em compreender aspectos legais, que não dominam a elaboração de projeto ou o planejamento de seu negócio no longo prazo, e ainda não tiveram anteriormente a cultura de crédito de longo prazo desenvolvida.

v Ponto positivo: 59,4\% dos financiamentos são para pessoas que possuem renda familiar mensal de até $\mathrm{R} \$ 3.000,00$, ou seja, pessoas que se enquadram no máximo na classe $\mathrm{C}$, segundo critério de classe econômica de Neri (2011).

\subsection{Dados gerais}

O objetivo desta seção é apresentar os dados gerais do Nossocrédito desde a sua implantação em 2003. Nesse sentido, a tabela 2 mostra que o Programa passou de 445 operações, em 2004, para mais de 18 mil, em 2012, um crescimento médio anual de 84,0\%. No que diz respeito a valor, os montantes financiados pelo Nossocrédito passaram de R \$1,8 milhão, em 2004, para R\$ 91,7 milhões, em 2012, uma expansão anual média de 88,7\%. A título de comparação, o saldo das operações de crédito do Sistema Financeiro no Espírito Santo (BCB, 2013) teve um aumento médio, em igual período, de $15,3 \%$ ao ano, um percentual bem inferior ao verificado para o Nossocrédito.

Do ponto de vista geográfico, o gráfico 1 mostra a distribuição entre os municípios capixabas dos financiamentos do Nossocrédito em termos de quantidade de operações entre 2003 e 2012. Nesse quesito, o primeiro lugar foi Cachoeiro de Itapemirim com mais de 3,9 mil operações, ao passo que Santa Leopoldina foi o último com apenas 250 operações. Além disso, outras informações que merecem destaque:

v os cinco municípios com maior número de operações (Cachoeiro de Itapemirim, Linhares, Serra, Colatina e São Mateus) representam 18,7\% do total;

、 já os cinco municípios com menor quantidade de operações (Santa Teresa, Laranja da Terra, Itarana, Bom Jesus do Norte e Santa Leopoldina) representam apenas 2\% do total; 
v os municípios da Grande Vitória (Vila Velha, Serra, Cariacica e Vitória), que são os mais populosos, representam 11,1\% do total de operações no período. Agregando a esse percentual as participações de Viana, Guarapari e Fundão, chega-se a 17\% do total de operações do estado;

、 os municípios do interior (exclui os da Grande Vitória) respondem por 83\% das operações do Nossocrédito.

Tabela 2

Financiamentos aprovados pelo Nossocrédito (2003-12)

\begin{tabular}{|ccccc|}
\hline Anos & Quantidade & Taxa de crescimento (\%) & Valor (R\$ de 2012)* $^{*}$ & Taxa de crescimento (\%) \\
\hline 2003 (set./dez.) & 53 & - & 227.006 & - \\
2004 & 445 & - & 1.838 .107 & - \\
2005 & 2.051 & 360,9 & 8.844 .054 & 381,2 \\
2006 & 5.741 & 179,9 & 24.204 .587 & 173,7 \\
2007 & 8.576 & 49,4 & 35.019 .193 & 44,7 \\
2008 & 8.597 & 0,2 & 35.215 .579 & 0,6 \\
2009 & 10.084 & 17,3 & 50.002 .365 & 42,0 \\
2010 & 11.760 & 16,6 & 60.158 .850 & 20,3 \\
2011 & 14.577 & 24,0 & 77.678 .637 & 29,1 \\
2012 & 18.019 & 23,6 & 91.777 .722 & 18,2 \\
\hline
\end{tabular}

Fonte: Bandes (2013).

Nota: deflacionado pelo Índice de Preços ao Consumidor Amplo (IPCA) do IBGE.

Já o gráfico 2 mostra a distribuição entre os municípios capixabas dos financiamentos do Nossocrédito em termos de valor das operações entre 2003 e 2012. Nesse critério, o primeiro lugar foi Linhares com mais de $\mathrm{R} \$ 21,3$ milhões em financiamento, enquanto Santa Leopoldina foi o último lugar com apenas R\$ 851 mil. Ademais, outras informações que merecem destaque:

จ os cinco municípios com maior número de financiamentos aprovados (Linhares, Cachoeiro de Itapemirim, Colatina, Serra e Guarapari) representam 19,4\% do total;

、 já os cinco municípios com menor quantidade de operações (Laranja da Terra, Mucurici, Itarana, Bom Jesus do Norte e Santa Leopoldina) representam apenas 1,8\% do total;

- os municípios da Grande Vitória (Vila Velha, Serra, Cariacica e Vitória), que são os mais populosos e têm os maiores PIBs, representam 10,7\% do total financiado no período. Agregando a esse percentual as participações de Viana, Guarapari e Fundão, chega-se a 16,5\% do total financiado no estado;

จ os municípios do interior (exclui os da Grande Vitória) respondem por 83,5\% dos financiamentos do Nossocrédito. 


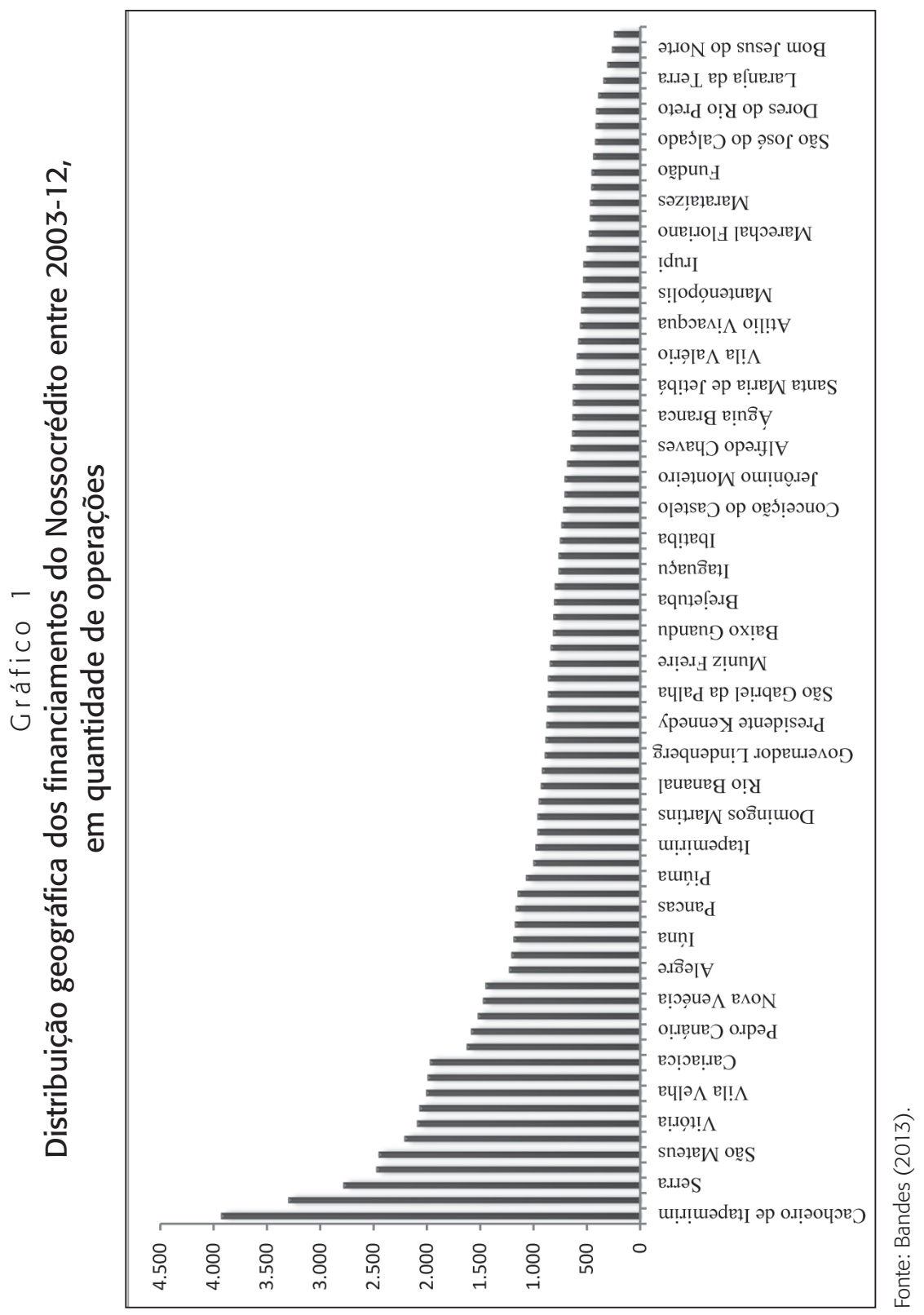




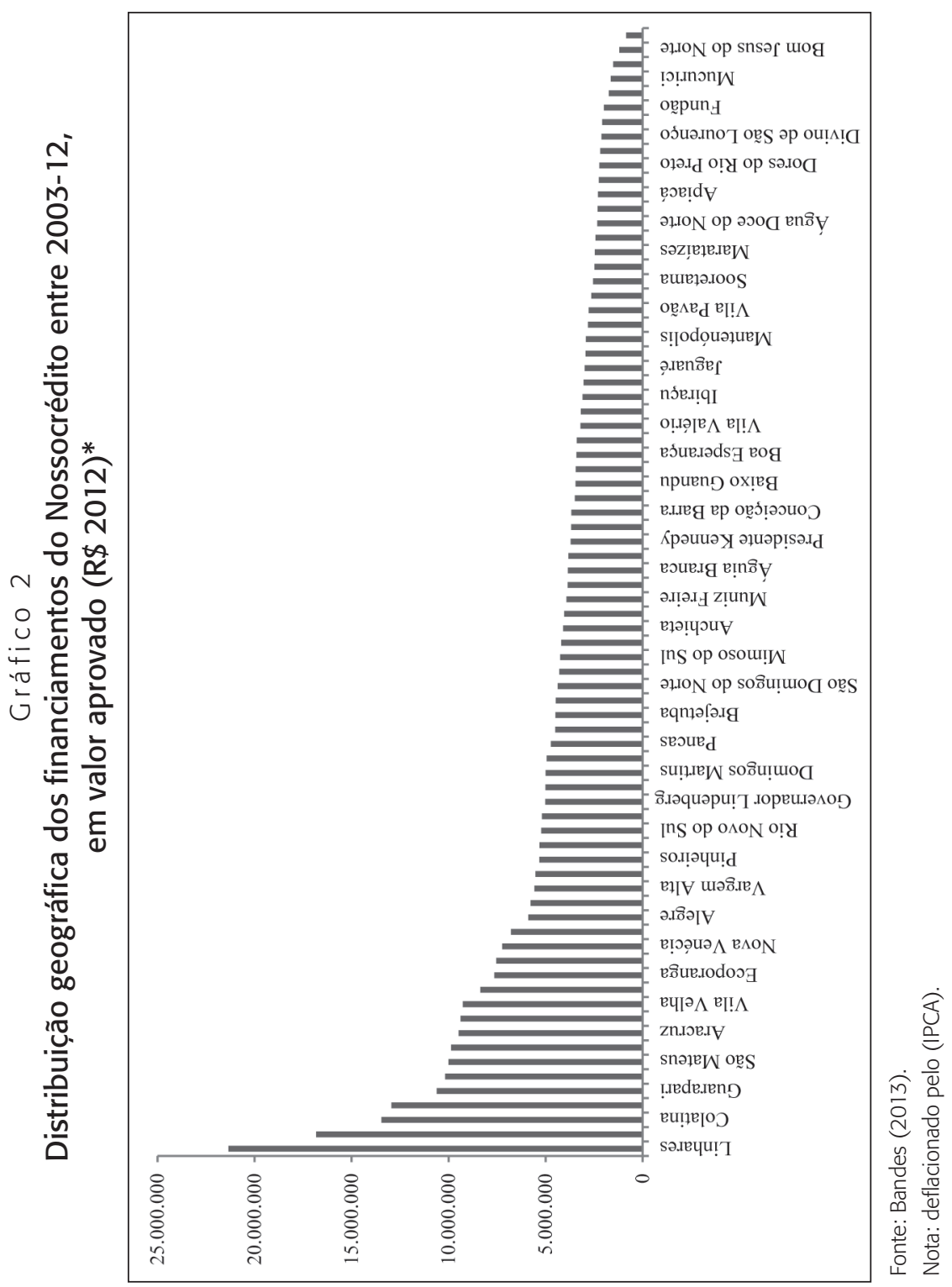


Outra informação importante é o ticket médio, ou seja, o valor médio de financiamento aprovado por cliente. O gráfico 3 mostra que entre 2003 e 2008 o ticket girou em torno de R\$ 4 mil, passando para cerca de R\$ 5 mil entre 2009 e 2012.

\section{Gráfico 3}

Ticket médio do Nossocrédito entre 2003-12 (R\$2012)*

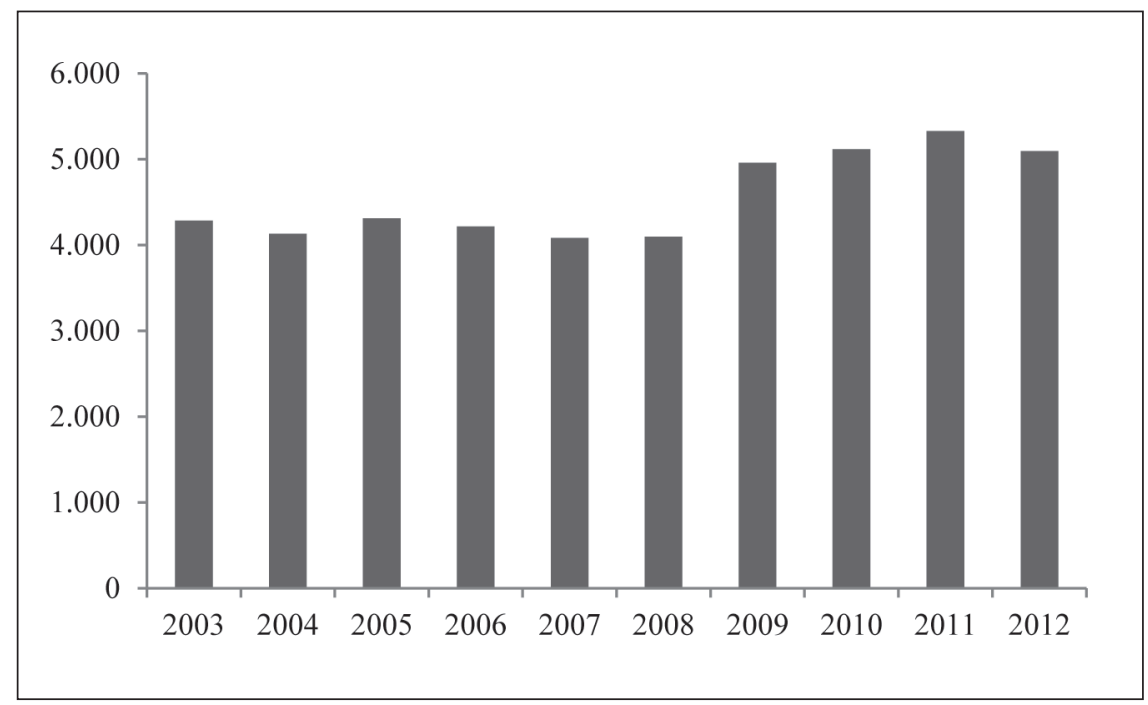

Fonte: Bandes (2013).

Nota: deflacionado pelo IPCA.

As informações apresentadas nos gráficos anteriores são importantes, mas não respondem a seguinte pergunta: o crédito ofertado tem sido suficiente para suprir a demanda dos municípios capixabas? Uma resposta a essa pergunta pode ser obtida ao usar o Índice Regional de Crédito (IRC), elaborado por Crocco e Figueiredo (2008) e Nogueira e colaboradores (2010a), que é uma adaptação do conhecido "quociente locacional”, amplamente utilizado na literatura de economia regional para determinar a existência ou não de especialização produtiva em uma região específica. Segue abaixo sua fórmula:

$$
\text { IRC }_{\mathrm{i}}=\frac{\frac{C R E D_{i}}{C R E D_{e s}}}{\frac{P I B_{i}}{P I B_{e s}}}
$$

Na equação 1 é apresentado o valor aprovado pelo Nossocrédito para o município "i" $\left(\mathrm{CRED}_{\mathrm{i}}\right)$, o valor aprovado pelo Nossocrédito para o Espírito Santo $\left(\mathrm{CRED}_{\mathrm{es}}\right)$, o PIB do município "i” ( $\mathrm{PIB}_{\mathrm{i}}$ ) e o PIB do Espírito Santo (PIB ${ }_{\mathrm{es}}$ ). Formando, portanto, o IRC do município "i” $\left(I R C_{\mathrm{i}}\right)$. Se o IRC for maior que um, que é o dado estimado para o Espírito Santo, pode-se dizer que a oferta de microcrédito é adequada à demanda local. 
Nessa linha, o gráfico 4 mostra os resultados obtidos a partir da equação 1 para os municípios capixabas com base nos dados de $2012 .{ }^{3}$ Nessa ótica, 70 municípios (90\% do total capixaba) apresentaram IRC maior do que um, ou seja, apresentam uma oferta de microcrédito adequada. Em outras palavras, o Nossocrédito tem cumprido um dos objetivos estratégicos do governo estadual e do Bandes de interiorizar o desenvolvimento, já que quase todos esses 70 municípios estão no interior capixaba, com exceção de Guarapari e Viana.

Porém, vale destacar que esses 70 municípios representam 25,9\% e 48,6\% do PIB e população do Espírito Santo, respectivamente. Isso mostra que é preciso intensificar o Nossocrédito na Região Metropolitana e alguns municípios economicamente importantes do interior, como Cachoeiro de Itapemirim.

Índice Regional de Crédito (IRC) do Nossocrédito em 2012, por município

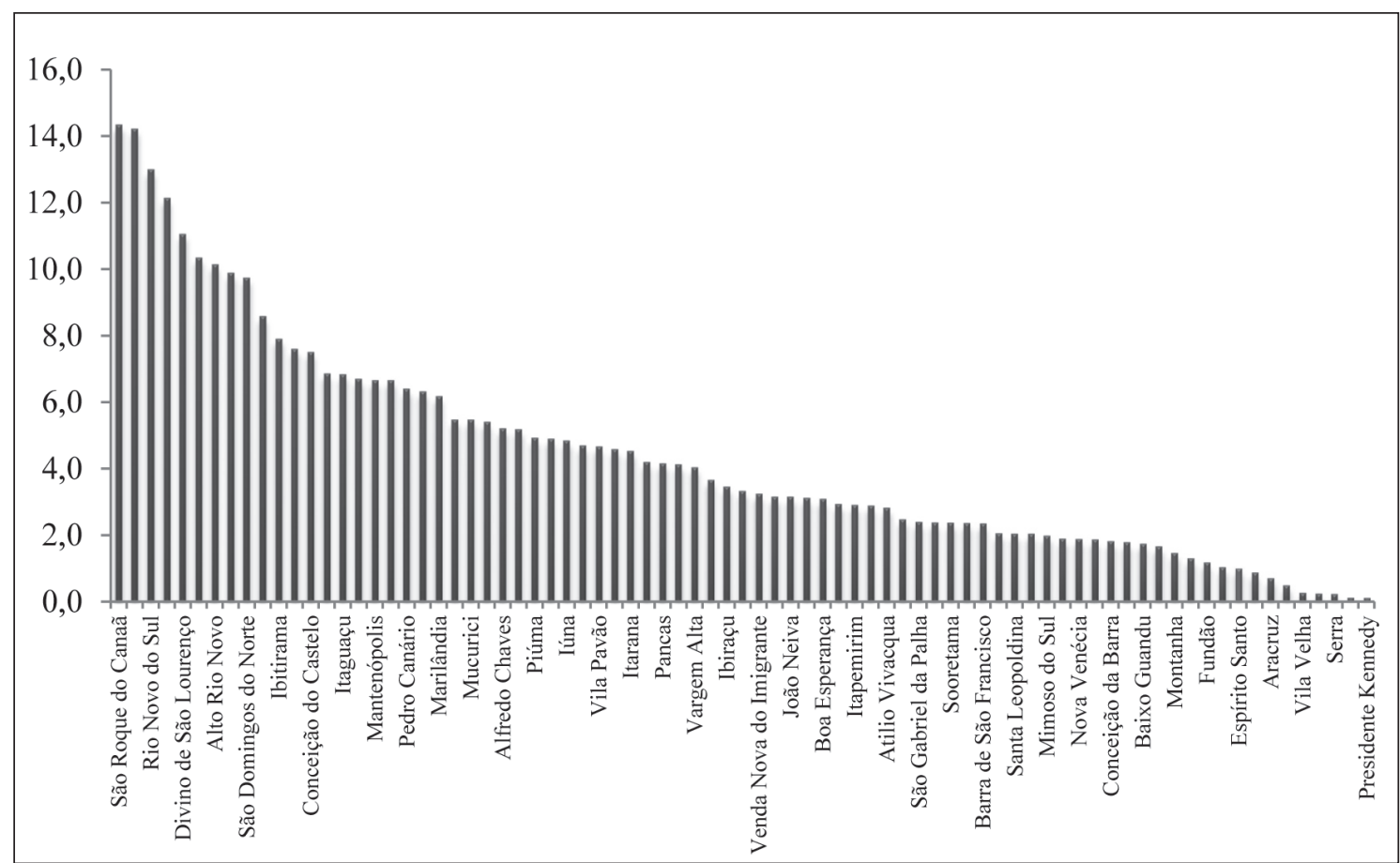

Fonte: Elaboração própria.

\footnotetext{
${ }^{3}$ Os dados municipais do PIB em 2012 foram estimados a partir de projeções que o Instituto Jones dos Santos Neves (IJSN, 2013) faz trimestralmente sobre o PIB capixaba. Para isso, considerou-se que a participação dos municípios no PIB total do estado não se modificou desde 2010, último ano em que os PIBs municipais calculados pelo IBGE estão disponíveis.
} 
Os oito municípios que apresentaram IRC inferior a um foram: Cachoeiro de Itapemirim, Aracruz, Cariacica, Vila Velha, Anchieta, Serra, Vitória e Presidente Kennedy. Além disso, é preciso procurar uma relação empírica que explique esse fato. Como o gráfico 5 mostra, existe uma correlação negativa entre a participação municipal no PIB capixaba e o IRC, ou seja, quanto maior a participação do município no PIB estadual, menor tende a ser o seu IRC.

Contudo, algumas características peculiares desses municípios podem ter levado a um IRC menor. Por isso, esses dados precisam ser relativizados:

i) Aracruz, Anchieta e Presidente Kennedy são municípios relativamente pouco populosos, mas de elevado PIB per capita por conta de grandes plantas industriais, nos dois primeiros casos, e de royalties de petróleo no caso de Presidente Kennedy.

ii) os demais municípios (Cariacica, Serra, Vila Velha, Vitória e Cachoeiro de Itapemirim) estão entre os de maior PIB do estado.

iii) como nesses casos o valor financiado pelo Nossocrédito é de magnitude pequena em face da participação municipal no PIB capixaba, o IRC tendeu a ser menor que um.

Gráfico 5

Correlação entre a participação municipal no PIB estadual e o IRC do Nossocrédito em 2012

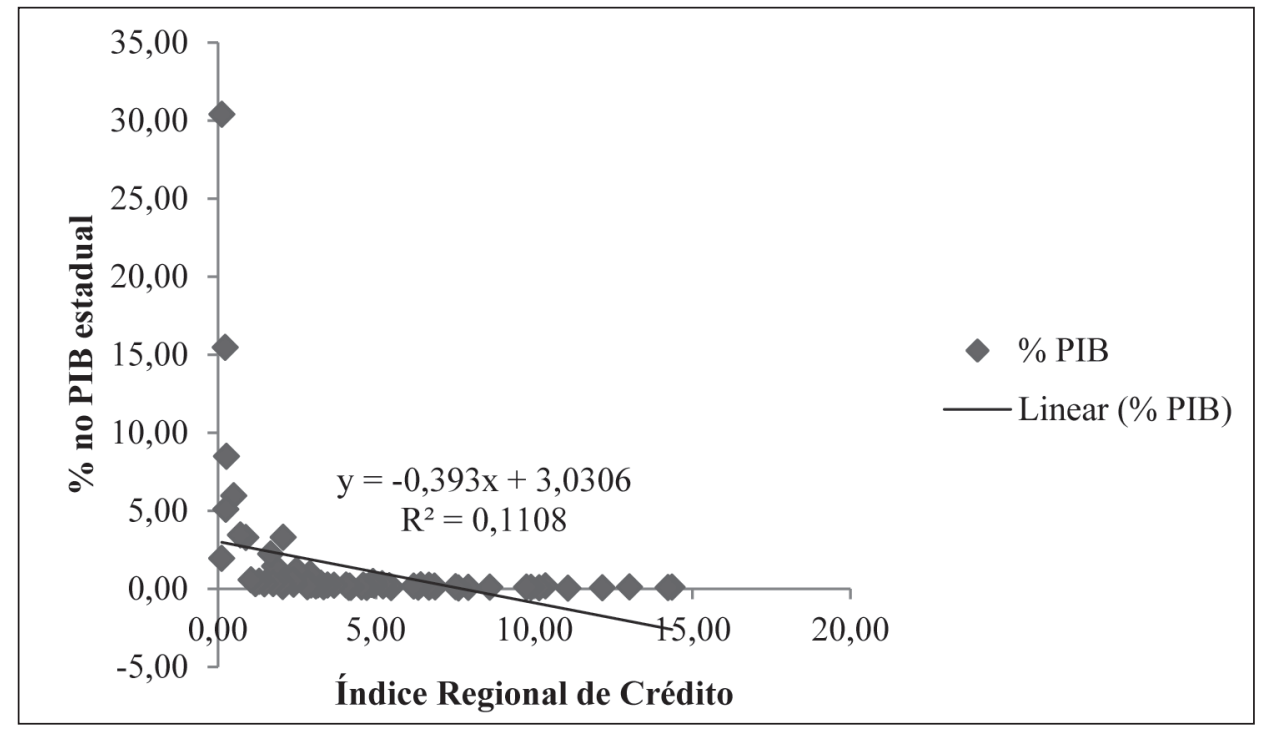

Fonte: Elaboração própria.

Complementando a análise anterior, pode-se usar o coeficiente de correlação de Pearson. Ele varia de -1 (correlação negativa perfeita) a 1 (correlação positiva perfeita), o sinal indica direção positiva ou negativa do relacionamento e o valor sugere a força da relação entre as variáveis. No caso das variáveis "participação municipal no PIB estadual" e "IRC do 
Nossocrédito", a correlação de Pearson é de -0,3392 (estatisticamente significante a 1\%), o que é considerado uma correlação negativa moderada, ratificando o padrão de correlação exibido no gráfico 5 .

\section{Avaliação dos impactos do Nossocrédito}

\subsection{Procedimentos empíricos e base de dados}

Metodologicamente, o presente trabalho empregou três modelos diferentes para avaliar o impacto socioeconômico do Nossocrédito nos municípios capixabas. O primeiro modelo a ser estimado é o seguinte:

$$
C R E D p c_{i t}=\beta_{1}+\beta_{2} \text { IBPpc }_{i t}+\beta_{3} \text { POBRE }_{i t}+\beta_{4} \text { IFDM }_{i t}+\beta_{5} \text { Dummy }+\varepsilon_{i t},
$$

onde:

- $C R E D p c_{i t}$ é o logaritmo natural dos financiamentos aprovados per capita pelo Nossocrédito no município i e no período $t$, respectivamente;

จ $\beta_{1}$ é o coeficiente linear, também chamado de termo do intercepto, que, hipoteticamente, é o valor que $P I B p c_{i t}$ assume quando $C R E D P c_{i t}$ for zero;

$\checkmark P I B p c_{i t}$ é o logaritmo natural do PIB per capita do município $i$ no período $t$;

、 $P O B R E_{i t}$ é o logaritmo natural do número de famílias pobres do município $i$ no período $t$;

、 $I F D M_{i t}$ é o logaritmo natural do Índice Firjan de Desenvolvimento Municipal (IFDM) do município $i$ no período $t$;

、 Dummy é a variável usada para medir a desconcentração geográfica do Nossocrédito, assumindo 1 para Vitória, Serra e Cariacica e 0 para os demais municípios;

、 $\varepsilon_{i t} e ́$ o termo que representa variáveis explicativas não incluídas no modelo.

O objetivo desse modelo é saber qual é a relação entre financiamentos aprovados per capita, PIB per capita, o número de famílias pobres e o IFDM dos municípios. Se a aprovação dos recursos do Nossocrédito responder puramente à demanda dos empreendedores (formais ou informais) ou das empresas de microporte, essa relação deve ser positiva, já que os municípios mais ricos (PIB per capita maior) e com menor número de famílias pobres demandariam mais recursos do programa. Se as aprovações tivessem como objetivo principal reduzir as desigualdades intrarregionais e de renda, essa relação deveria ser negativa: quanto menor o PIB per capita e maior o número de famílias pobres, maior o crédito per capita para aquele município. 
Com relação à variável dummy, a proposta é verificar se a distribuição geográfica do Nossocrédito foi concentrada ou não nos municípios da Grande Vitória que fazem parte da amostra, a saber, Vitória, Serra e Cariacica. A justificativa para isso é que esses municípios somaram, em média, $58,2 \%$ do PIB da amostra usado no trabalho no período 2006-10.

Além disso, alguns pontos devem ser esclarecidos sobre o porquê se trabalhou com dados de PIB e financiamentos per capita nas estimativas. Primeiro, per capita nesse caso significa um valor médio para cada indivíduo, supondo que todos receberam a mesma quantia, seja em termos de financiamento, seja em termos de PIB. Segundo, a transformação de uma série de dados em per capita é uma forma de normalizá-la e, ademais, permite comparar estatísticas entre municípios de forma mais adequada, uma vez que isso neutraliza, pelo menos em parte, as diferenças entre as mesmas no que tange à magnitude de população e de economia.

O segundo modelo a ser estimado é o seguinte:

$$
\operatorname{IFDM}_{i t}=\beta_{1}+\beta_{2} \operatorname{CREDpc}_{i t}+\beta_{3} \text { PIBpc }_{i t}+\beta_{4} P O P_{i t}+\varepsilon_{i t}
$$

onde:

จ $\operatorname{IFDM}_{i t}$ é o logaritmo natural do Índice Firjan de Desenvolvimento Municipal (IFDM) do município $i$ no período $t$;

จ $\beta_{1}$ é o coeficiente linear, também chamado de termo do intercepto, que, hipoteticamente, é o valor que $I F D M_{i t}$ assume quando $C R E D p c_{i t}$ for zero;

- $C R E D p c_{i t}$ é o logaritmo natural dos financiamentos aprovados per capita pelo Nossocrédito no município $i$ e no período $t$, respectivamente;

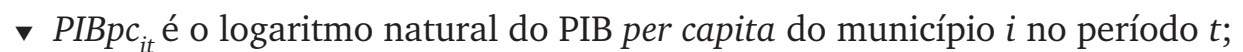

、 $P O P_{i t}$ é o logaritmo natural da população do município $i$ no ano $t$;

$\checkmark \varepsilon_{i t}$ é o termo que representa variáveis explicativas não incluídas no modelo.

O objetivo desse modelo é saber qual o tipo de relação existente entre IFDM e financiamentos aprovados per capita, PIB per capita e a população dos municípios. Se a aprovação dos recursos do Nossocrédito for positiva, o programa contribui para a melhoria do desenvolvimento dos municípios. Se as aprovações tiverem resultado negativo, pode-se concluir que o programa não contribui efetivamente para expansão do bem-estar das localidades.

O terceiro modelo a ser estimado é o seguinte:

$$
\mathrm{POBRE}_{i t}=\beta_{1}+\beta_{2} \mathrm{CREDpc}_{i t}+\beta_{3} \mathrm{PIBpc}_{i t}+\beta_{4} \mathrm{POP}_{i t}+\varepsilon_{i t}
$$

onde:

、 $P O B R E_{i t}$ é o logaritmo natural do número de famílias pobres do município $i$ no período $t$; 
、 $\beta_{1}$ é o coeficiente linear, também chamado de termo do intercepto, que, hipoteticamente, é o valor que $P O B R E_{i t}$ assume quando $C R E D p c_{i t}$ for zero;

- CREDpc $c_{i t}$ é o logaritmo natural dos financiamentos aprovados per capita pelo Nossocrédito no município $i$ e no período $t$, respectivamente;

、 $P I B p c_{i t}$ é o logaritmo natural do PIB per capita do município $i$ no período $t$;

$\checkmark P O P_{i t}$ é o logaritmo natural da população do município $i$ no ano $t$;

$\checkmark \varepsilon_{i t}$ é o termo que representa variáveis explicativas não incluídas no modelo.

O objetivo desse modelo é saber que tipo de relação existe entre o número de famílias pobres e os financiamentos aprovados per capita, PIB per capita e a população dos municípios. Se a aprovação dos recursos do Nossocrédito for positiva, o programa não contribui para a redução da quantidade de famílias pobres nos municípios. Se as aprovações tiverem resultado negativo, pode-se concluir que o programa contribui efetivamente para diminuição da pobreza.

Nos três modelos propostos, usou-se logaritmo natural tanto nas variáveis dependentes como nas explicativas pelas seguintes razões, tomando como base Gujarati (2000:cap. 6):

\ Primeiro, com o objetivo de normalizar os dados usados nas estimativas;

、 E, segundo, com o intuito de se estimar o que Gujarati (2000:156) chama de modelo log-linear.

Uma característica atraente do modelo log-linear é que seus coeficientes de inclinação, $\beta_{2}$, $\beta_{3}$ e $\beta_{4}$, medem a elasticidade da variável dependente $\left(P I B p c_{i t}, I F D M_{i t}, P O B R E_{i t}\right.$ e POP $P_{i t}$ nos três modelos) com relação à variável explicativa ( $C R E D p c_{i t}$ nos três modelos), ou seja, uma variação percentual na primeira para uma dada variação percentual na variável explicativa.

As fontes das estatísticas são descritas no quadro 1.

Quadro 1

Variáveis e fontes usadas nas estimativas

\begin{tabular}{|llll|}
\hline \multicolumn{1}{|c|}{ Variável } & \multicolumn{1}{c|}{ Descrição } & Fonte \\
\hline PIB per capita & Calculado a partir da razão entre PIB e população de cada município & IBGE (2013) \\
População & Estimativas da população residente em nível municipal & IBGE (2014) \\
& Calculado a partir da média aritmética simples de três componentes & Firjan (2013) \\
IFDM & $\begin{array}{l}\text { relativos a indicadores de Educação, Saúde e Emprego e Renda, e } \\
\text { varia entre 0 e } 1\end{array}$ & Equivale à quantidade de famílias inscritas no Cadastro Único para & \\
Número de famílias pobres & Programas Sociais (Cadúnico) com renda per capita mensal de até & MDS (2013) \\
Valor de financiamento per capita & R\$ 140,00 & Calculado a partir da razão entre valor de financiamento do & Bandes (2013) \\
do Nossocrédito & Nossocrédito e população de cada município & \\
\hline
\end{tabular}

Fonte: Elaboração própria. 
Os dados cobrem o período 2006-10 e foram deflacionados pelo Índice de Preços ao Consumidor Amplo (IPCA) do IBGE, no caso das variáveis monetárias. A tabela 3 resume as estatísticas descritivas das variáveis utilizadas no estudo.

Tabela 3

\section{Estatísticas descritivas}

\begin{tabular}{|lccccc|}
\hline \multicolumn{1}{|c}{ Variável } & Observações & Média & Desvio Padrão & Mínimo & Máximo \\
\hline PIB per capita 2006 & 76 & 14.136 & 12.313 & 6.462 & 75.589 \\
PIB per capita 2007 & 76 & 17.018 & 15.191 & 7.700 & 87.300 \\
PIB per capita 2008 & 76 & 18.267 & 23.511 & 7.886 & 155.095 \\
PIB per capita 2009 & 76 & 16.165 & 18.548 & 7.617 & 135.029 \\
PIB per capita 2010 & 76 & 19.921 & 31.327 & 7.662 & 209.133 \\
População 2006 & 76 & 39.817 & 72.184 & 5.354 & 394.370 \\
População 2007 & 76 & 38.444 & 71.034 & 4.837 & 385.370 \\
População 2008 & 76 & 39.639 & 72.628 & 4.997 & 397.226 \\
População 2009 & 76 & 39.996 & 73.582 & 5.011 & 404.688 \\
População 2010 & 76 & 40.345 & 73.198 & 4.516 & 409.267 \\
IFDM 2006 & 76 & 0,669 & 0,070 & 0,539 & 0,864 \\
IFDM 2007 & 76 & 0,676 & 0,068 & 0,537 & 0,867 \\
IFDM 2008 & 76 & 0,678 & 0,066 & 0,544 & 0,884 \\
IFDM 2009 & 76 & 0,693 & 0,060 & 0,579 & 0,884 \\
IFDM 2010 & 76 & 0,712 & 0,057 & 0,624 & 0,894 \\
№ famílias pobres 2006 & 76 & $2.826,34$ & $3.539,04$ & 513 & 20.749 \\
№ famílias pobres 2007 & 76 & $3.038,48$ & $3.906,28$ & 499 & 23.117 \\
№ famílias pobres 2008 & 76 & $3.123,05$ & $4.050,70$ & 550 & 22.937 \\
№ famílias pobres 2009 & 76 & $3.081,03$ & $4.101,60$ & 575 & 24.688 \\
№ famílias pobres 2010 & 76 & $3.272,52$ & $4.385,68$ & 630 & 25.508 \\
Financiamento per capita 2006 & 76 & 11,41 & 9,11 & 0,86 & 49,25 \\
Financiamento per capita 2007 & 76 & 22,52 & 15,68 & 2,49 & 104,59 \\
Financiamento per capita 2008 & 76 & 23,17 & 17,10 & 1,44 & 94,88 \\
Financiamento per capita 2009 & 76 & 33,50 & 26,59 & 2,24 & 132,47 \\
Financiamento per capita 2010 & 76 & 36,87 & 27,51 & 2,14 & 124,69 \\
\hline
\end{tabular}

Fonte: Elaboração própria.

Ressalta-se que o Espírito Santo possui 78 municípios. No entanto, o Nossocrédito só começou a operar em Santa Maria de Jetibá em 2007 e em Vila Velha em 2009. Por isso, esses municípios foram excluídos das estimativas. 


\subsection{Resultados}

Neste item são apresentados os resultados referentes às estimativas realizadas para os dois modelos. Para estimar os três modelos é usada a técnica de MQO. A referência usada para os procedimentos empíricos é Wooldridge (2011).

Na tabela 4 são apresentados os resultados do primeiro modelo (equação 2). Todos os coeficientes estão em logaritmo natural, assim eles representam elasticidades, isto é, é uma alteração percentual na variável dependente para uma dada variação percentual na variável explicativa, mantido o resto constante. Foram conduzidos o teste de White, que verifica a presença de heterocedasticidade na regressão, e o teste de Durbin-Watson, que analisa a existência de autocorrelação serial na estimativa. De acordo com os resultados da tabela 4, os dois problemas foram encontrados na regressão, o que foi retificado por meio da regressão robusta de Newey-West.

Heterocedasticidade e autocorrelação são violações das hipóteses básicas dos modelos de regressão linear, tais como os propostos neste artigo. A primeira significa que a variância dos erros não é constante, tornando os estimadores viesados. Já autocorrelação significa a correlação de uma variável com valores defasados (com diferenças no tempo) dela mesma e, na sua presença, o estimador de mínimos quadrados ordinários não tem a menor variância possível entre todos os estimadores, o que o torna viesado e inconsistente. O teste de White é frequentemente usado para se identificar a presença de heterocedasticidade nos resíduos de uma regressão e é feito com base na hipótese nula de que não há heterocedasticidade. Já o teste de Durbin-Watson é muito empregado para se identificar a autocorrelação e sua hipótese nula testa a ausência de autocorrelação serial de primeira ordem. Valores de Durbin-Watson menores que 1,5 evidenciam correlação serial positiva e valores maiores que 2,5 indicam correlação serial negativa.

Além disso, o teste $\mathrm{F}$ mostra que globalmente a estimativa é significante. Depois, o $\mathrm{R}^{2}$ ajustado mostra que $27,9 \%$ da variância do valor per capita do crédito é explicada pelas variáveis independentes. $O \beta_{2}$ não se mostrou significativo, mas o seu sinal negativo mostra que quanto menor o PIB per capita do município, maior o crédito per capita para aquele município. Já o $\beta_{3}$ se mostrou significativo e seu sinal positivo mostra que, quanto maior o número de pobres do município, maior o crédito per capita para ele. E $\beta_{4}$ também se mostrou significativo e o seu sinal positivo evidencia que, quanto maior o IFDM, maior o crédito per capita para aquele município. Por fim, a variável dummy apontou que os três de maior renda da amostra (Vitória, Serra e Cariacica) receberam 0,63\% menos crédito per capita do que os demais.

Nesse sentido, o programa contribui para amenizar um dos problemas da economia capixaba, qual seja, a grande concentração regional da renda, dado que 58\% do PIB está aglomerado nos três municípios citados anteriormente. Isso porque grande parte dos municípios de menor PIB per capita do estado está no interior. Contudo, os resultados das estimativas também indicam que o programa precisa focar mais nos municípios com menor desenvolvimento, já que crédito tem sido mais direcionado para os de maior IFDM. 
Tabela 4

Relação entre o Nossocrédito, PIB per capita e no de famílias pobres dos municípios capixabas, (2006-10)

\begin{tabular}{|c|c|c|c|c|}
\hline Variáveis & Coeficientes & Erro-padrão & Valor $\mathrm{t}$ & P-valor \\
\hline$\beta_{1}$ (Intercepto) & 9,76513 & 1,17431 & 8,31562 & 0,00000 \\
\hline $\mathrm{L} \beta_{2}(\mathrm{PIBPc})$ & $-0,03513$ & 0,08636 & $-0,40681$ & 0,68440 \\
\hline $\mathrm{L} \beta_{3}(\mathrm{POBRE})$ & 0,55430 & 0,07137 & 7,76689 & 0,00000 \\
\hline$L \beta_{4}($ IFDM $)$ & 2,10818 & 0,68672 & 3,06993 & 0,00230 \\
\hline Dummy & $-0,63515$ & 0,18481 & $-3,43679$ & 0,00070 \\
\hline \multicolumn{5}{|c|}{$\mathrm{R}^{2}$ ajustado $=0,2787 \quad$ Teste $\mathrm{F}=37,6275[0,0000]$} \\
\hline
\end{tabular}

Fonte: Elaborada pelo autor a partir dos dados da pesquisa.

Nota: $L$ indica que as variáveis estão expressas em logaritmos.

Na tabela 5 são apresentados os resultados do modelo que analisa o impacto do Nossocrédito no IFDM dos municípios espírito-santenses. O teste $\mathrm{F}$ confirmou que a regressão é globalmente significante e pode ser considerada eficiente. Ademais, o $\mathrm{R}^{2}$ ajustado mostra que $59,8 \%$ da variância de IFDM são explicados pelas variáveis independentes. Por fim, o teste White não detectou a presença de heterocedasticidade e o teste Durbin-Watson identificou um problema de autocorrelação, o que foi retificado por meio do uso da correção AR(1), que envolve o uso do estimador de mínimos quadrados generalizados que leva em conta a presença de autocorrelação serial de primeira ordem e é o estimador eficiente neste caso.

Tabela 5

Impacto do Nossocrédito no IFDM dos municípios capixabas (2006-10)

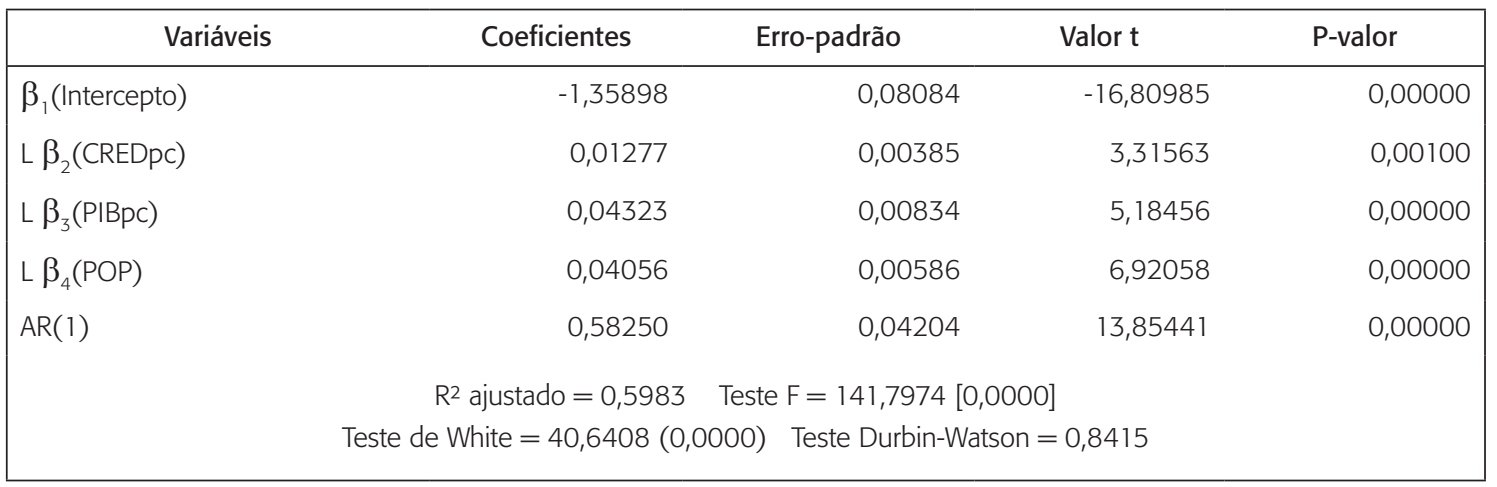

Fonte: Elaborada pelo autor a partir dos dados da pesquisa.

Nota: $L$ indica que as variáveis estão expressas em logaritmos. 
Ainda na tabela 5, o crédito per capita se mostra significativo e positivo. Isso mostra que o impacto do Nossocrédito no IFDM contribuiu, embora modestamente $(0,012 \%)$, para a melhoria desse indicador de desenvolvimento municipal. Esse resultado é coerente com o obtido na tabela 4 anterior, visto que os municípios de maior IFDM foram os que receberam mais crédito. Além disso, o PIB per capita e a população contribuíram mais para a melhora do IFDM do que o crédito per capita.

Finalmente, a tabela 6 mostra os resultados do terceiro modelo (equação 4), que analisa o efeito do Nossocrédito sobre a quantidade de famílias pobres. O teste F confirmou que a estimativa é globalmente significante. Além disso, o $\mathrm{R}^{2}$ ajustado mostra que 93,6\% da variância do $\mathrm{n}$ o de famílias pobres é explicada pelas variáveis independentes. Por fim, o teste White não detectou a presença de heterocedasticidade e o teste Durbin-Watson identificou a presença de autocorrelação, o que foi ajustado por meio da correção AR(1).

Tabela 6

Impacto do Nossocrédito no no de famílias pobres dos municípios capixabas (2006-10)

\begin{tabular}{|c|c|c|c|c|}
\hline Variáveis & Coeficientes & Erro-padrão & Valor $\mathrm{t}$ & P-valor \\
\hline$\beta_{1}$ (Intercepto) & $-0,75662$ & 0,28597 & $-2,64579$ & 0,00850 \\
\hline L $\beta_{2}($ CREDPC) & 0,04687 & 0,01268 & 3,69740 & 0,00030 \\
\hline $\mathrm{L} \beta_{3}(\mathrm{PIBpC})$ & 0,02206 & 0,02950 & 0,74794 & 0,45500 \\
\hline$L \beta_{4}(\mathrm{POP})$ & 0,75941 & 0,02138 & 35,51417 & 0,00000 \\
\hline $\operatorname{AR}(1)$ & 0,74040 & 0,03469 & 21,34606 & 0,00000 \\
\hline \multicolumn{5}{|c|}{$\mathrm{R}^{2}$ ajustado $=0,9364$ Teste $\mathrm{F}=1394,36[0,0000]$} \\
\hline \multicolumn{5}{|c|}{ Teste de White $=18,4606(0,0302)$ Teste Durbin-Watson $=0,5248$} \\
\hline
\end{tabular}

Fonte: Elaborada pelo autor a partir dos dados da pesquisa.

Nota: $L$ indica que as variáveis estão expressas em logaritmos.

Quanto aos resultados da tabela 6, o crédito per capita se mostra significativo e positivo, evidenciando que o impacto do Nossocrédito no no de famílias pobres não contribuiu para a redução da pobreza nos municípios capixabas. Uma hipótese aqui aventada para explicar esse resultado é que, como foi visto na seção 3.2, apenas 15\% dos clientes do Nossocrédito têm renda familiar mensal de até 1.500,00 e 3,5\% dos financiamentos do programa estão na faixa entre $\mathrm{R} \$ 200,00$ e R\$1.000,00, o que é factível para o conceito de pobreza aqui empregado. Em outras palavras, isso ratifica os resultados exibidos na tabela 4 de que o Programa Nossocrédito precisa focar as pessoas de menor renda, pois são justamente as que têm mais dificuldade no acesso ao sistema financeiro tradicional. 


\section{Considerações finais}

O objetivo do presente trabalho foi analisar empiricamente a contribuição do Nossocrédito para a melhoria de indicadores socioeconômicos dos municípios capixabas. De maneira geral, a participação do programa no total de operações de crédito do Espírito Santo é muito pequena, 0,46\% em 2012. Entretanto, 70 municípios (90\% do total capixaba) apresentaram IRC maior do que um, ou seja, em tese apresentam uma oferta de microcrédito adequada. Porém, vale destacar que esses municípios representam $25,9 \%$ e 48,6\% do PIB e população do Espírito Santo, respectivamente.

Além disso, foram conduzidas estimativas econométricas com três modelos distintos, usando a técnica de MQO e uma base de dados municipais para o período 2006-10. Os principais resultados encontrados foram os seguintes:

10 modelo: os resultados mostraram que o programa contribui para amenizar o problema da economia capixaba de concentração regional da renda ao direcionar mais o crédito para os municípios do interior do que para os da Grande Vitória que compõem a amostra (Vitória, Serra e Cariacica); todavia, o programa precisa melhorar seu foco e disponibilizar mais crédito para as pessoas de menor renda;

$2^{\circ}$ modelo: o coeficiente estimado se mostrou significativo e positivo, evidenciando que o efeito do Nossocrédito no IFDM contribuiu modestamente para a melhoria desse indicador de desenvolvimento municipal;

3o modelo: o coeficiente regredido se mostrou significativo e positivo, mostrando que o impacto do Nossocrédito no no de famílias pobres não contribuiu para a redução da pobreza nos municípios capixabas. Uma explicação para isso é que apenas $15 \%$ dos clientes do Nossocrédito têm renda familiar mensal de até $1.500,00$ e 3,5\% dos financiamentos do programa estão na faixa entre $\mathrm{R} \$ 200,00$ e $\mathrm{R} \$ 1.000,00$.

Em suma, pode-se concluir que o Programa Nossocrédito, criado pelo governo do Espírito Santo e executado, grosso modo, pelas duas instituições financeiras majoritariamente controladas pela administração estadual - Bandes e Banestes - tem contribuído para a melhoria do bem-estar nos municípios espírito-santenses, embora precise melhorar seu foco e direcionar mais recursos para os mais pobres, que são os que mais enfrentam dificuldades para acessar o sistema financeiro tradicional.

Por fim, como sugestão de pesquisa futura e com o objetivo de avaliar continuamente a efetividade dos programas públicos de desenvolvimento, recomenda-se a condução de uma pesquisa usando a técnica de randomized evalution trial, tal como em Banerjee e colaboradores (2009).

\section{Referências}

AMADO, Adriana M. Bancos privados e públicos regionais em uma perspectiva de desenvolvimento regional. In: JAYME JR., Frederico G.; CROCCO, Marco (Org.). Bancos públicos e desenvolvimento. Rio de Janeiro: Ipea, 2010. cap. 7. 
ARRAES, Ronaldo A.; SILVA, Lúcia de Fátima B. Demanda por microcrédito no Nordeste: atuação dos pequenos empresários. Revista Econômica do Nordeste, v. 41, n. 2, p. 375-396, abr./jun. 2010. BANCO CENTRAL DO BRASIL (BCB). Estatísticas operacionais sobre o Sistema Financeiro no Espírito Santo. Disponível em: <www.bcb.gov.br>. Acesso em: 16 maio 2013.

BANCO DE DESENVOLVIMENTO DO ESPÍRITO SANTO (BANDES). Relatórios de desempenho do Nossocrédito (vários anos). Vitória: Bandes, 2013.

BANERJEE, Abhijit et al. The miracle of microfinance? Evidence from a randomized evaluation, 2009. Disponível em: <http://economics.mit.edu/files/4162>. Acesso em: 30 março 2013.

BARGER, Teresa. Financial institutions. Washington: IFC, 1998.

BRAGA, Márcio B.; TONETO JÚNIOR, Rudinei. Microcrédito: aspectos teóricos e experiências. Análise Econômica, v. 18, n. 33, p. 69-86, 2000.

CHAVES, Sydnei S. Diagnóstico e desafios do microcrédito no Brasil. Revista Desenbahia, n. 15, p. 193-228, set. 2011.

CROCCO, Marco; FIGUEIREDO, Ana Teresa L. Estratégias bancárias diferenciadas no território: uma análise exploratória. In: ENCONTRO INTERNACIONAL DA ASSOCIAÇÃO BRASILEIRA KEYNESIANA, I, Campinas, 2008.

DOW, Sheila C. Financial markets and regional economic development: the Canadian experience. Aldershot: Averbury, 1990.

DOW, Sheila C. The regional composition of the money multiplier process. Scottish Journal of Political Economy, v. 19, n. 1, p. 22-44, fev. 1982.

DOW, Sheila C. The treatment of money in regional economics. Journal of Regional Economics, v. 27, n. 1, p. 13-24, fev. 1987.

DUTRA, Leonardo R. Análise de concessão de microcrédito e sua relação com a inadimplência: um estudo no Banestes e Bandes. Dissertação (mestrado) — Fundação Instituto Capixaba de Pesquisas em Contabilidade, Economia e Finanças, Vitória, 2010.

ESTRELLA, Juliana. O efeito do microcrédito como uma política de redução de desigualdade de oportunidades e melhoria de bem-estar. Tese (doutorado em ciência política) - Instituto Universitário de Pesquisas do Rio de Janeiro, Rio de Janeiro. 2008.

FEDERAÇÃO DAS INDÚSTRIAS DO ESTADO DO RIO DE JANEIRO (Firjan). Estatísticas do Índice Firjan de Desenvolvimento Municipal dos municípios do Espírito Santo. 2013. Disponível em: <www. ifdm.firjan.org.br>. Acesso em: 3 jun. 2013.

FREITAS, Ana Augusta; RIBEIRO, Rosa. Análise segmentada da performance empreendedora de tomadores de microcrédito. Revista Econômica do Nordeste, v. 40, n. 2, p. 249-261, abr./jun. 2009.

FREITAS, Ana Paula G.; PAULA, Luiz Fernando R. Concentração regional do crédito e consolidação bancária no Brasil: uma análise pós-real. Revista Economia, v. 11, n. 1, p. 97-123, jan./abr. 2010. 
GIUBERTI, Inez F. R. Programa Nossocrédito: uma análise do processo de formulação e implementação do programa de microcrédito do Estado do Espírito Santo. Dissertação (mestrado) - Centro de Ciências Jurídicas e Econômicas, Universidade Federal do Espírito Santo, Vitória, 2008.

GUJARATI, Damodar. Econometria básica. 3. ed. São Paulo: Pearson Makron Books, 2000.

INSTITUTO BRASILEIRO DE GEOGRAFIA E ESTATÍSTICA (IBGE). Estatísticas de PIB dos municípios do Espírito Santo. 2013. Disponível em: <www.sidra.ibge.gov.br>. Acesso em: 3 jun. 2013.

INSTITUTO BRASILEIRO DE GEOGRAFIA E ESTATÍSTICA (IBGE). Estatísticas de população dos municípios do Espírito Santo. 2014. Disponível em: <www.sidra.ibge.gov.br> . Acesso em: 18 jul. 2014. INSTITUTO DE PESQUISA ECONÔMICA E APLICADA (Ipea). Bancos: exclusão e serviços. Brasília: Ipea, 2011.

INSTITUTO JONES DOS SANTOS NEVES (IJSN). Estimativas do PIB trimestral do Espírito Santo. 2013. Disponível em: <www.ijsn.es.gov.br>. Acesso em: 3 jun. 2013.

KING, Robert; LEVINE, Ross. Finance and growth: Schumpeter might be right. The Quaterly Journal of Economics, v. 108, n. 3, p. 717-737, ago. 1993.

MAZZUTTI, Caio. Microfinanças no Brasil: afinal, existe um trade-off entre o foco na pobreza e a sustentabilidade financeira? Dissertação (mestrado) - Universidade Federal do Rio Grande do Sul, Porto Alegre, 2005.

MENEZES, Melissa et al. Sistema financeiro e desenvolvimento regional: notas exploratórias. In: PAULA, Luiz F.; OREIRO, José L. Sistema financeiro: uma análise do setor bancário brasileiro. Rio de Janeiro: Elsevier, 2007.

MINISTÉRIO DO DESENVOLVIMENTO SOCIAL E COMBATE À FOME (MDS). Estatísticas de famílias pobres dos municípios do Espírito Santo. 2013. Disponível em: <http://aplicacoes.mds.gov.br/sagi/ mi2007/tabelas/mi_social.php>. Acesso em: 3 jun. 2013.

MOTA, Wilton L.; SANTANA, José Ricardo. O microcrédito como estratégia de redução da pobreza no Nordeste: uma avaliação a partir do programa Crediamigo. Revista Econômica do Nordeste, v. 42, n. 1, p. 25-48, jan./mar. 2011.

NERI, Marcelo C. A nova classe média: o lado brilhante da base da pirâmide. Rio de Janeiro: Saraiva, 2011.

NERI, Marcelo C. Microcrédito: o mistério nordestino e o Grameen brasileiro: perfil e performance dos clientes do Crediamigo. Rio de Janeiro: FGV, 2008.

NERI, Marcelo C.; GIOVANINI, Fabiano da S. Negócios nanicos, garantias e acesso à crédito. Revista de Economia Contemporânea, v. 9, n. 3, p. 643-669, 2005.

NERI, Marcelo C.; MEDRADO, André Luiz. Experimentando microcrédito: uma análise de impacto do Crediamigo no acesso a crédito. Revista Econômica do Nordeste, v. 41, n. 1, p. 133-154, jan./ mar. 2010. 
NOGUEIRA, Mara; CROCCO, Marco; FIGUEIREDO, Ana Teresa. Estratégias bancárias diferenciadas no território: o caso de Minas Gerais. Análise Econômica, v. 28, n. 54, p. 281-311, set. 2010a.

NOGUEIRA, Mara; CROCCO, Marco; SANTOS, Fabiana. Sistema financeiro e atuação dos bancos públicos no desenvolvimento regional no Brasil. In: JAYME JR., Frederico G.; CROCCO, Marco (Org.). Bancos públicos e desenvolvimento. Rio de Janeiro: Ipea, 2010b.

PIMENTEL, Vinícius; KERSTENETZKY, Celia Lessa. Microcrédito: por que os bancos privados não bancam? Faculdade de Economia da Universidade Federal Fluminense. Texto para discussão n. 242, jul. 2008.

PREMOLI, Marcus Vinícius. Avaliação de processo em políticas e programas públicos: o caso do programa de microcrédito Nossocrédito - ES. Dissertação (mestrado) - Universidade Federal de Viçosa, Viçosa, 2011.

REICHSTUL, Daniel; LIMA, Gilberto T. Causalidade entre crédito bancário e nível de atividade econômica na Região Metropolitana de São Paulo: algumas evidências empíricas. Revista Estudos Econômicos, v. 36, n. 4, p. 779-801, out./dez. 2006.

SOARES, Marden; SOBRINHO, Abelardo. Microfinanças: o papel do Banco Central do Brasil e a importância do cooperativismo de crédito. Brasília: BCB, 2007.

SOARES, Ricardo B. et al. Condicionantes da saída da pobreza com microcrédito: o caso dos clientes do Crediamigo. Estudos Econômicos, v. 41, n. 1, p. 119-142, jan./mar. 2011.

STIGLITZ, Joseph. The role of the state in financial markets. The World Bank, Annual Bank Conference on Development Economics, Washington D.C., 1993.

STIGLITZ, Joseph; WEISS, Andrew. Credit rationing in markets with imperfect information. The American Economic Review, v. 71, n. 3, p. 393-410, jun. 1981.

WOOLDRIDGE, Jeffrey. M. Introdução à econometria: uma abordagem moderna. 4. ed. São Paulo: Cengage Learning, 2011.

Sávio Bertochi Caçador é mestre em economia pela Universidade Federal do Espírito Santo (Ufes) e economista do Banco de Desenvolvimento do Espírito Santo (Bandes). E-mail: sbcacador@hotmail.com. 